\title{
Pengaruh Kombinasi Pupuk NPK dan Pupuk Hayati terhadap Populasi Total Mikroba Tanah dan Hasil Jagung Manis (Zea mays L. saccharata) pada Inceptisols Jatinangor
}

\author{
Septyani Sofatin 1), Betty Natalie Fitriatin'2), dan Yuliati Machfud ${ }^{2)}$
}

1) Alumni Program Studi Agroteknologi Fakultas Pertanian Universitas Padjadjaran

2) Staff Pengajar Departemen Ilmu Tanah dan Sumberdaya Laha, Fakultas Pertanian Universitas Padjadjaran, Jl. Raya Bandung Sumedang Km 21 Jatinangor

Korespondensi: septyani94@gmail.com

\begin{abstract}
Biofertilizer and $N, P, K$ fertilizer combination is expected to decreased the application dosage of inorganic $N, P, K$ fertilizer and increased the yield of maize. This experiment was conducted to describe the effect of $N, P, K$ fertilizer and biofertilizer combination to the population total of soil microbes and yield of maize (Zea mays L. saccharata) on Inceptisols Jatinangor. This experiment was carried out Ciparanje Experimental Station, Faculty of Agriculture, Universitas Padjadjaran, Jatinangor with altitude 820 meters from October 2015 to January 2016. This experiment was arranged in randomized block design which consisted of ten combinations and three replications. Ten combinations were: control; NPK standard dosage; biofertilizer standard dosage; $1 / 4$ of NPK +1 of biofertilizer; $1 / 2$ of NPK +1 of biofertilizer; $3 / 4$ of NPK dosage +1 of biofertilizer; 1 of NPK +1 of biofertilizer; $3 / 4$ of NPK $+1 / 4$ of biofertilizer; $3 / 4$ of NPK $+1 / 2$ of biofertilizer; and $3 / 4$ of $N P K+3 / 4$ of biofertilizer. The experiment showed that the combination of NPK and biofertilizer gave a significant effect to increased yield of maize. The standard dosage of biofertilizer reduced $50 \%$ of the NPK application and increased the yield of maize by 13,85\% efficiently.
\end{abstract}

Keywords: biofertilizer, NPK uptake, soil microbe, maize

\section{PENDAHULUAN}

Jagung manis (Zea mays L. saccharata) merupakan jenis jagung yang pemanfaatannya semakin meluas dan permintaan pasar yang semakin tinggi. Produktivitas tanaman jagung setiap tahunnya hingga tahun 2015 terus meningkat dengan 3,17 \% per tahun dengan angka produktivitas sebesar 5,18 ton ha ${ }^{-1}$ dan produksi sebesar 19,61 juta ton pada tahun 2015 (Badan Pusat Statistik, 2016). Dalam memenuhi kebutuhan produksi nasional, Indonesia masih mengimpor. Hingga tahun 2013 laju impor terus meningkat sebesar 1,43 $\%$ setiap tahunnya, sedangkan ekspor jagung manis mengalami penurunan hingga 17,25 \% (Badan Pusat Statistik, 2014). Upaya yang dapat dilakukan untuk meningkatkan produksi adalah dengan melakukan pemupukan.

Pemupukan dilakukan untuk menyediakan dan memenuhi kebutuhan hara tanaman jagung. Pemupukan dengan pupuk anorganik yang biasa digunakan oleh petani yaitu pupuk NPK dalam bentuk Urea, SP 36, dan KCl. Unsur hara N, P, dan K merupakan hara esensial bagi tanaman sehingga, unsur-unsur ini harus selalu tersedia dalam tanah.

Seringkali petani memberikan pupuk anorganik dalam jumlah yang berlebihan dan terus menerus yang dapat mengakibatkan rusaknya fisik, kimia, dan biologi tanah serta menurunkan kesuburan tanah. Upaya yang dapat dilakukan untuk mengurangi dampak penggunaan pupuk anorganik adalah dengan penambahan pupuk hayati yang dapat memperbaiki sifat tanah serta menambah kandungan unsur hara pada tanah.

Menurut Permentan No. 70 tahun 2011, pupuk hayati adalah produk biologi aktif terdiri atas mikroba yang dapat meningkatkan efisiensi pemupukan, kesuburan, dan kesehatan tanah. Pupuk hayati termasuk ke dalam bahan pembenah tanah yang dapat mening- 
katkan kandungan unsur hara pada tanah. Prinsip penggunaan pupuk hayati adalah dengan memanfaatkan kerja mikroorganisme tertentu dalam tanah yang berperan sebagai dekomposer, membantu proses mineralisasi, dan bersimbiosis dengan tanaman dalam menambat unsur hara sehingga unsur hara tersebut tersedia bagi tanaman, dan memacu pertumbuhan tanaman serta sebagai agen biokontrol yang tidak berbahaya bagi proses ekologi dan lingkungan (Simanungkalit, 2009).

Peranan pupuk anorganik tidak sepenuhnya dapat digantikan oleh pupuk hayati. Salah satu solusi yang dapat dilakukan adalah melakukan pemupukan dengan pupuk kombinasi antara pupuk anorganik dan pupuk hayati. Aplikasi pupuk hayati dan pupuk NPK $50 \%$ dari dosis anjuran dapat meningkatkan produksi jagung (Fadiluddin, 2009). Mikroba yang terdapat dalam pupuk hayati dapat berguna untuk merombak bahan organik yang tersedia dalam tanah sehingga dapat diserap oleh tanaman.

Kelompok mikroba yang sering digunakan dalam pupuk hayati adalah kelompok mikroba yang mampu menyediakan unsur makro bagi tanaman yaitu unsur N, P, dan $\mathrm{K}$. Mikroba-mikroba tersebut adalah mikroba penambat $\mathrm{N}$ dari udara serta mikroba pelarut hara $\mathrm{P}$ dan $\mathrm{K}$ dalam tanah. Kelompok mikroba tersebut adalah Rhizobium sp., Azospirilium sp., dan Azotobacter sp., yang berfungsi untuk memfiksasi nitrogen, Aspergilus sp., Pseudomonas sp., dan Lactobacillus sp. berfungsi untuk melarutkan fosfat dan kalium.

Berdasarkan uraian di atas, maka aplikasi kombinasi pupuk NPK dan pupuk hayati pada penelitian ini diharapkan memberikan pengaruh terhadap populasi mikroba total dalam tanah dan hasil jagung manis (Zea mays L. saccharata) pada Inceptisols Jatinangor.

\section{BAHAN DAN METODE}

Penelitian dilaksanakan di Kebun Percobaan Ciparanje, Fakultas Pertanian,
Universitas Padjadjaran, Kab. Sumedang, Jawa Barat dengan ketinggian $820 \mathrm{mdpl}$ dengan ordo tanah Inceptisol. Analisis dilakukan di Laboratorium Biologi dan Bioteknologi Tanah serta Laboratorium Kesuburan Tanah dan Nutrisi Tanaman Departemen Ilmu Tanah dan Sumber Daya Lahan, Fakultas Pertanian, Universitas Padjadjaran. Penelitian ini dilaksanakan dari bulan Oktober 2015 sampai Januari 2016.

Bahan yang digunakan dalam penelitian ini terdiri atas:

- benih jagung manis varietas hibrida Bonanza

- pupuk hayati cair

- pupuk kandang

- pupuk tunggal Urea $(45 \% \mathrm{~N}), \mathrm{SP}-36$ $\left(36 \% \mathrm{P}_{2} \mathrm{O}_{5}\right)$, dan $\mathrm{KCl}\left(60 \% \mathrm{~K}_{2} \mathrm{O}\right)$

- insektisida berbahan aktif prefonofos dengan merk dagang "Curacron $500 \mathrm{EC}$ "

- media NA dan PDA untuk analisis populasi mikroba tanah

Parameter utama penelitian ini terdiri dari populasi mikroba total hasil jagung manis. Rancangan yang digunakan berupa Rancangan Acak Kelompok (RAK) yang terdiri dari 10 (sepuluh) perlakuan kombinasi pemupukan yaitu:
A. Tanpa pupuk (kontrol)
B. NPK standar
C. 1 pupuk hayati $(\mathrm{PH})$
D. $1 / 4 \mathrm{NPK}+1 \mathrm{PH}$
E. $1 / 2 \mathrm{NPK}+1 \mathrm{PH}$
F. $3 / 4 \mathrm{NPK}+1 \mathrm{PH}$
G. $1 \mathrm{NPK}+1 \mathrm{PH}$
H. $3 / 4 \mathrm{NPK}+1 / 4 \mathrm{PH}$
I. $3 / 4 \mathrm{NPK}+1 / 2 \mathrm{PH}$
J. $3 / 4 \mathrm{NPK}+3 / 4 \mathrm{PH}$

Seluruh perlakuan diulang sebanyak tiga kali. Data hasil pengamatan dianalisis secara statistik menggunakan program SPSS. Uji $\mathrm{F}$ pada taraf nyata $5 \%$ dilakukan untuk melihat 
pengaruh perlakuan. Apabila pengaruh perlakuan berbeda nyata, maka dilanjutkan dengan uji Duncan pada taraf nyata 5\%.

\section{HASIL DAN PEMBAHASAN}

\subsection{Populasi Total Mikroba Tanah}

Hasil analisis sidik ragam populasi jamur dan populasi bakteri menunjukkan bahwa kombinasi pupuk NPK dengan pupuk hayati tidak berpengaruh nyata terhadap populasi jamur maupun populasi bakteri. Hal tersebut diduga disebabkan karena komposisi kandungan mikroba total dalam pupuk hayati yang diaplikasikan mengandung kepadatan populasi mikroba yang cukup tinggi yaitu sebesar $1,07 \times 10^{5} \mathrm{CFU} \mathrm{ml} \mathrm{ml}^{-1}$ untuk populasi jamur dan sebesar $8,1 \times 10^{9} \mathrm{CFU} \mathrm{ml}^{-1}$ untuk populasi bakteri.

Perkembangan populasi mikroba tanah yang tidak dapat beradaptasi pada lingkungan serta tidak dapat berkompetisi dengan bakteri indigenous yang populasinya cukup tinggi yaitu $3,25 \times 10^{4} \mathrm{CFU} \mathrm{g}^{-1}$ untuk populasi total jamur dan $2,0 \times 10^{8} \mathrm{CFU} \mathrm{ml}^{-1}$ untuk populasi total bakteri. Simanungkalit dkk. (2012) menyebutkan bahwa Rhizobium tidak mampu berkembang dan bertahan hidup pada lingkungan yang baru dan kondisi tercekam, seperti kondisi tanah yang masam, serta kemampuannya bersaing dengan mikroba indigenous sejenis yang telah beradaptasi dengan baik dalam lingkungannya menyebabkan mikroba lain tidak dapat berkembang dengan baik.

Populasi mikroba dalam tanah selain dipengaruhi oleh faktor abiotik seperti suhu, kelembaban, tekstur tanah, dan ketersediaan serta konsentrasi unsur hara di dalam tanah (Simanungkalit dkk., 2012). Ketersediaan serta konsentrasi unsur hara yang berasal dari aplikasi pupuk anorganik NPK menyebabkan unsur hara dalam tanah meningkat dan menurunkan populasi mikroba dalam tanah.

Menurut Fitriatin dkk. (2009), peningkatan dosis pupuk $\mathrm{P}$ menyebabkan populasi MPF se-makin berkurang karena sumber $\mathrm{P}$ yang ter-dapat dalam tanah tidak dapat dimanfaatkan secara maksimal bahkan menghambat per-tumbuhan MPF maupun mikroorganisme indigenous.

Tabel 1 Pengaruh Kombinasi Pupuk NPK dan Pupuk Hayati terhadap Populasi Total Mikroba Tanah

\begin{tabular}{lcc}
\hline \multicolumn{1}{c}{ Perlakuan } & $\begin{array}{c}\text { Populasi } \\
\text { Jamur } \\
\text { (CFUx10 }\end{array}$ & $\begin{array}{c}\text { Populasi } \\
\text { Bakteri } \\
(\text { CFUx10 })\end{array}$ \\
\hline Kontrol & 14,32 & 7,35 \\
NPK standar & 7,96 & 9,00 \\
1 Pupuk Hayati (PH) & 12,33 & 21,21 \\
1/4 NPK + 1 Pupuk Hayati & 17,74 & 11,69 \\
1/2 NPK + 1 Pupuk Hayati & 19,28 & 11,17 \\
3/4 NPK + 1 Pupuk Hayati & 20,33 & 8,13 \\
1 NPK + 1 Pupuk Hayati & 12,37 & 9,28 \\
3/4 NPK + 1/4Pupuk Hayati & 17,14 & 8,50 \\
3/4 NPK + 1/2 Pupuk Hayati & 17,60 & 10,31 \\
3/4 NPK + 3/4 Pupuk Hayati & 14,74 & 13,42 \\
\hline Keterangan : Nilai rata-rata & perlakuan yang tidak \\
\multicolumn{4}{c}{ diberi notasi huruf tidak berpengaruh } \\
nyata menurut uji Jarak & Berganda \\
Duncan pada taraf nyata 5 \%.
\end{tabular}

\subsection{Hasil Jagung Manis}

Hasil analisis sidik ragam terhadap hasil jagung manis menunjukkan bahwa kombinasi pupuk NPK dengan pupuk hayati berpengaruh nyata terhadap hasil jagung manis. Tabel 2 menunjukkan bahwa 1 dosis rekomendasi pupuk hayati mampu menekan penggunaan pupuk NPK hingga $1 / 2$ dosis rekomendasi, dengan efisiensi pupuk hingga $50 \%$ kombinasi ini dapat meningkat hasil hingga 13,85 \% disbandingkan dengan pemupukan NPK dosis rekomendasi.

Tingkat efisiensi pemupukan NPK yang lebih baik terdapat pada perlakuan kombinasi $1 / 2$ dosis rekomendasi NPK dan 1 dosis rekomendasi pupuk hayati yang menghasilkan jagung manis sebanyak 29,00 ton ha-1 dengan peningkatan sebesar 36,59 \% dibandingkan dengan perlakuan Kontrol. Hal ini sesuai dengan pernyataan Fadiluddin (2009) bahwa aplikasi pupuk hayati dan pupuk NPK $50 \%$ 
dari dosis anjuran dapat meningkatkan produksi jagung.

Tabel 2 Pengaruh Kombinasi Pupuk NPK dengan Pupuk Hayati terhadap Hasil Jagung Manis

\begin{tabular}{lcc}
\hline \multicolumn{1}{c}{ Perlakuan } & $\begin{array}{c}\text { Hasil } \\
\text { (g per } \\
\text { tanaman) }\end{array}$ & $\begin{array}{c}\text { Hasil } \\
\text { (ton ha-1) }\end{array}$ \\
\hline Kontrol & $398,00 \mathrm{~b}$ & 21,23 \\
NPK standar & $477,67 \mathrm{bc}$ & 25,47 \\
1 Pupuk Hayati (PH) & $399,67 \mathrm{~b}$ & 21,31 \\
1/4 NPK + 1 Pupuk Hayati & $363,67 \mathrm{ab}$ & 19,39 \\
1/2 NPK + 1 Pupuk Hayati & $543,83 \mathrm{c}$ & 29,00 \\
3/4 NPK + 1 Pupuk Hayati & $458,00 \mathrm{bc}$ & 24,43 \\
1 NPK + 1 Pupuk Hayati & $436,00 \mathrm{bc}$ & 23,25 \\
3/4 NPK + 1/4Pupuk Hayati & 358,00 ab & 19,09 \\
3/4 NPK + 1/2 Pupuk Hayati & 479,67 bc & 25,58 \\
3/4 NPK + 3/4 Pupuk Hayati & 246,67 a & 13,15 \\
\hline Keterangan : Nilai rata-rata perlakuan yang tidak \\
diberi notasi huruf tidak berpengaruh \\
nyata menurut uji Jarak Berganda \\
Duncan pada taraf nyata $5 \%$
\end{tabular}

Penggunaan kombinasi $1 / 2$ dosis rekomendasi NPK +1 dosis rekomendasi pupuk hayati selain dapat menekan penggunaan pupuk anorganik NPK sebesar $50 \%$ juga dapat memberikan pengaruh yang lebih baik terhadap pertumbuhan dan hasil tanaman jagung, serta produktivitas yang lebih tinggi dibanding kombinasi 1 NPK +1 pupuk hayati (Purwanti dkk., 2014). Berdasarkan deskripsi jagung manis varietas hibrida Bonanza, kapasitas hasil produksi jagung manis hibrida Bonanza dengan pemupukan NPK berimbang sesuai dosis rekomendasi berkisar antara 1216 ton ha-1 ${ }^{-1}$ sehingga jumlah pada setiap perlakuan sudah memenuhi kapasitas hasil yang optimal.

Aplikasi kombinasi pupuk NPK dan pupuk hayati pada jagung manis dapat memenuhi kebutuhan unsur hara yang cukup bagi tanaman. Pupuk anorganik NPK dapat secara langsung menyediakan unsur hara yang dapat diserap oleh tanaman, sedangkan kandu- ngan beberapa jenis mikroba yang terdapat dalam pupuk hayati mampu membantu meningkatkan ketersediaan unsur hara terutama unsur makro NPK di dalam tanah. Mikroba mampu mengikat $\mathrm{N}_{2}$ di udara serta melarutkan $\mathrm{P}$ dan $\mathrm{K}$ menjadi bentuk tersedia, sehingga kebutuhan akan unsur hara tanaman selama fase vegetatif dan fase generatif terpenuhi.

Kombinasi pupuk NPK dan pupuk hayati dengan hasil terbaik pada perlakuan menunjukkan bahwa aplikasi pupuk hayati dapat menekan penggunaan pupuk anorganik sebesar $50 \%$ dari dosis rekomendasi. Perlakuan ini juga berpengaruh baik terhadap pertumbuhan tanaman karena pemupukan yang berimbang antara pupuk NPK dengan pupuk hayati. Pemupukan berimbang bertujuan untuk mencapai unsur hara esensial seimbang sesuai kebutuhan tanaman agar tanaman dapat tumbuh optimal, hasil produksi dan mutu meningkat, efisiensi dalam pemupukan, kesuburan tanah terjaga serta menghindari pencemaran lingkungan (Departemen Pertanian, 2010).

\section{KESIMPULAN}

Kombinasi pupuk NPK dan pupuk hayati berpengaruh nyata terhadap hasil jagung manis, namun tidak berpengaruh nyata terhadap populasi mikroba total. Kombinasi $1 / 2$ dosis pupuk NPK dan 1 dosis pupuk hayati mampu menekan penggunaan pupuk NPK hingga $50 \%$ serta meningkatkan hasil jagung manis hingga 13,85 \% dibandingkan dengan dosis rekomendasi NPK pada Inceptisols Jatinangor.

\section{DAFTAR PUSTAKA}

Badan Pusat Statistik. 2014. Impor Ekspor Produk Pertanian Menurut Komoditi. Tersedia pada http://www.bps.go.id/all (Diakses pada 10 November 2015)

Badan Pusat Statistik. 2016. Produktivitas dan Produksi Jagung Menurut Provinsi 2010-2014. Tersedia pada http://www.pertanian.go.id/Data5tahu 


\section{n/TPASEM2015/33ProdtvJagung.pdf} (Diakses pada 17 April 2016)

Departemen Pertanian. 2010. Pemupukan Berimbang Spesifik Lokasi pada Tanaman Jagung. Tersedia pada http://deptan.go.id/ (Diakses pada 11 Maret 2016).

Fadiluddin, M. 2009. Efektivitas Formula Pupuk Hayati dalam Memacu Serapan Hara, Produksi, dan Kualitas Hasil Jagung dan Padi Gogo. Tesis. Sekolah Pascasarjana Institut Pertanian Bogor.

Fitriatin, B.N., Anni, Y., dan Tien T. 2014. Kandungan $\mathrm{P}$ tanah dan Pertumbuhan Jagung yang dipengaruhi oleh Aplikasi Mikroba Pelarut Fosfat dan Pupuk P pada Tanah Marginal. Makalah pada Seminar Nasional Himpunan Ilmu Tanah Indonesia (HITI) $16-17$ September 2014, Banda Aceh.

Fitriatin, B.N., A. Yuniarti., O. Mulyani., F.S. Fauziah., M.D. Tiara. 2009. Pengaruh mikroorganisme pelarut fosfat dan pupuk $\mathrm{P}$ terhadap $\mathrm{P}$ tersedia, aktivitas fosfatase, populasi mikroorganisme pelarut fosfat, konsentrasi $\mathrm{P}$ tanaman, dan hasil Padi Gogo (Oryza sativa L.) pada Ultisols. Jurnal Agrikultura, Vol. 20, (3), hal: 210 - 215.
PERMENTAN. 2011. Peraturan Menteri Pertanian Republik Indonesia tentang Pupuk Organik, Pupuk Hayati dan Pembenah Tanah. No 70/ Permentan/ SR. 140/10/2011.

Purwanti, L., Wawan, S., dan Kusumiyati. 2014. Pengaruh konsentrasi pupuk hayati dan dosis pupuk N, P, K terhadap pertumbuhan dan hasil tanaman jagung manis (Zea mays saccharataSturt.) kultivarTalenta. Jurnal Agric. Sci. J. Vol. I (4), hal: 177-188.

Simanungkalit, R.D.M. 2009. Aplikasi Pupuk Hayati dan Pupuk Kimia: Suatu Pendekatan Terpadu. Buletin Agrobio Vol 4 (2), hal 56-61.

Simanungkalit, R.D.M, D.A. Suriadikarta, R. Saraswati, D. Setyorini, dan W. Hartatik. 2012. Pupuk Organik dan Pupuk Hayati. Badan Penelitian dan Pengembangan Pertanian, Kementerian Pertanian.

Simanungkalit, R.D.M., Rasti, S., Ratih, D.H., dan Edi, H. 2012. Pupuk Organik dan Pupuk Hayati: Bakteri Penambat Nitrogen. Balai Penelitian Tanah. Badan Penelitian dan Pengembangan Pertanian, Kementerian Pertanian. 